Congressoem

Desenvolvimento Social

\section{Desafios à Democracia, Desenvolvimento e Bens Comuns}

\title{
A GLOBALIZAÇÃO E O NEOLIBERALISMO NAS OBRAS DE MILTON SANTOS E BOAVENTURA DE SOUSA SANTOS.
}

\author{
Nelson Souza Soares ${ }^{1}$ \\ Joyce Mayra Amarante Marcelino ${ }^{2}$ \\ Nívia Carlos de Oliveira Araújo ${ }^{3}$
}

\section{RESUMO}

O fenômeno da globalização surgiu a partir da intensificação de interações transnacionais nos setores financeiros, de produção e de comunicação e informação. Esse processo é multifacetado e abrange dimensões sociais, culturais, religiosas, econômicas e jurídicas interligadas de forma complexa. Nessa nova rede mundial, fundamentada em um consenso neoliberal baseada em um modelo de acumulação em escala global, acentuou-se a polarização entre a riqueza e a pobreza, o capital passou a exercer uma dominação de proporções mundiais através das multinacionais e agências financeiras controladas pelos Estados hegemônicos que comprimem a autonomia dos Estados periféricos buscando reduzir a regulação estatal na economia e os custos salariais dos trabalhadores. Neste trabalho discutimos os fenômenos da globalização e do neoliberalismo, considerando a situação de crise desses sistemas, a partir das obras "Os processos da globalização", do sociólogo português Boaventura de Sousa Santos e "Por uma outra globalização: do pensamento único a consciência universal", do geógrafo brasileiro Milton Santos, buscamos discorrer sobre a visão desses autores sobre os assuntos supracitados através de uma revisão de literatura. Procuramos refletir sobre questões relacionadas às tensões entre global e o local e sobre as perspectivas de desdobramentos desses fenômenos na obra dos referidos autores.

Palavras chaves: Globalização, Neoliberalismo, Sociedade global.

\section{GLOBALIZAÇÃO E NEOLIBERALISMO: CONCEITOS GERAIS.}

A partir da década de 1970, os avanços tecnológicos na área da informação e comunicação proporcionaram uma interação a nível global nunca vista em toda a história. Percebeu-se a necessidade de pensar o mundo de forma mais ampla, incluindo as relações e processos econômicos, políticos sócias e culturais em escala mundial, para Ianni (1994), as reflexões sobre as sociedades nacionais já não eram suficientes para a compreensão dos movimentos em uma sociedade global. Vários termos foram usados academicamente no intuito de descrever esse processo como cultura global, sistema global, cidades globais, aldeia global etc. Porém majoritariamente esse fenômeno e conhecido como globalização.

1 Departamento de Artes/ Unimontes e Conservatório estadual de música Lorenzo Fernandez.nelsonss13@ hotmail.com

$2 \quad$ Unimontes.jmamvcp@hotmail.com

3 Unimontes. nicarlosaraujo@gmail.com 
Congressoem

Desenvolvimento Social

\section{Desafios à Democracia, Desenvolvimento e Bens Comuns}

Alvarez (1999) afirma que a globalização é um conjunto heterogêneo surgido a partir da expansão das empresas multinacionais, do capital financeiro internacionalizado, da revolução na tecnologia de informação e telecomunicação, dos processos produtivos descentralizados, de Estados nacionais enfraquecidos, do fim do socialismo de Estado e da crescente influência mundial da cultural norte americana.

Para Guidens a globalização pode ser definida:

[...] como a intensificação das relações sociais em escala mundial, que ligam localidades distantes de tal maneira que acontecimentos locais são modelados por eventos ocorrendo a muitas milhas de distância e vice-versa. Este é um processo dialético porque tais acontecimentos locais podem se deslocar numa direção inversa às relações muito distanciadas que os modelam. A transformação local é tanto uma parte da globalização quanto a extensão lateral das conexões sociais através do tempo e espaço. Assim, quem quer que estude as cidades hoje em dia, em qualquer parte do mundo, está ciente de que o que ocorre numa vizinhança local tenda ser influenciado por fatores - tais como dinheiro mundial e mercados de bens - operando a uma distancia indefinida da vizinhança em questão. (1991, p. 69-70).

Ianni (1994) considera o processo de globalização é uma transição fundamental em que a reflexão a partir da sociedade nacional, está sendo subsumida por uma reflexão a nível global, haja vista que uma visão a partir de um estado nacional não é suficiente para compreendê-lo sem situá-lo em um contexto internacional. Para esse autor, portanto:

Ocorre que a sociedade global não é a mera extensão quantitativa e qualitativa da sociedade nacional. Ainda que esta continue a ser básica, evidente e indispensável, manifestando-se inclusive em âmbito internacional, é inegável que a sociedade global se constitui como uma realidade original, desconhecida, carente de interpretações. (IANNI, 1994, p.148)

Esse novos mecanismos globais se estruturaram em torno do capitalismo com a divisão internacional do trabalho e processos produtivos flexíveis. As empresas e corporações transnacionais se tornam agentes da internacionalização do capital e passam a interferir nas economias nacionais. (IANNI, 2001) A forma predominante de ação do capitalismo nesse processo é o chamado neoliberalismo.

Para Matos (2008), a ideologia neoliberal ganha força após a segunda guerra mundial, embora seu desenvolvimento inicial remonte ao início do século XX na chamada "Escola austríaca" a partir de autores como Carlos Menger e Ludwig Von Mises que se basearam no liberalismo econômico dos séculos XVIII e XIX, e pretendiam recuperam um suposto sentido original do liberalismo.

Em novembro 1989 ocorreu na capital dos EUA um encontro que ficou conhecido como "Consenso de Washington" realizado pelo Institute for internacional economics, com a presença de representantes do governo americano e de organismos internacionais como FMI e o Banco Mundial. Nesse encontro foi oficializado um receituário que já vinha sendo recomendado 
Congressoem

Desenvolvimento Social

\section{Desafios à Democracia, Desenvolvimento e Bens Comuns}

pelos países centrais desde a década de 1970. O FMI e o Banco mundial também já exigiam a adoção de algumas dessas medidas para aceitação de ações de cooperação econômica e concessão de empréstimos. Os termos do consenso se tornaram condições "para conceder cooperação financeira externa, bilateral ou multilateral; reunindo elementos até então esparsos em um único corpo teórico, que se tornou o mais novo paradigma da política econômica neoliberal". (MATOS, 2008, p.207)

Duménil e Lévy definem o neoliberalismo como:

[...] uma configuração de poder particular dentro do capitalismo, na qual o poder e a renda da classe capitalista foram restabelecidos depois de um período de retrocesso. Considerando o crescimento da renda financeira e o novo progresso das instituições financeiras, esse período pode ser descrito como uma nova hegemonia financeira, que faz lembrar as primeiras décadas do século XX nos EUA. (2007, p.2)

Duménil e Lévy (2007) consideram ainda que o neoliberalismo é uma espécie de novo imperialismo, onde os países mais avançados extraem lucro do resto do mundo, a abertura de fronteiras comerciais entre países de diferentes níveis de desenvolvimento configura uma violência econômica catastrófica para os países menos desenvolvidos, essa violência assume também outras formas através de práticas políticas e culturais, não podendo ser restrita ao campo econômico.

Nas próximas páginas discutiremos as visões sobre globalização, e consequentemente sobre o neoliberalismo a partir das obras "Os processos de globalização" do sociólogo português Boaventura de Sousa Santos, e "Por uma outra globalização" do geógrafo brasileiro Milton Santos.

\section{BOAVENTURA DE SOUSA SANTOS.}

Boaventura Santos entende a globalização como uma intensificação das interações transnacionais, globalização dos sistemas de produção, transferências financeiras e a disseminação em escala mundial de informações e imagens. Para esse autor trata-se de um "fenômeno multifacetado com dimensões econômicas, sociais, políticas e culturais, religiosas e jurídicas interligadas de modo complexo." (SANTOS, 2002,p.26) e que portanto deve ser interpretado levando em conta aspectos econômicos, políticos e culturais

A globalização para esse autor não é consensual, mas sim um campo de conflito social entre o periférico e o hegemônico (esse último orientado pelo Consenso de Washington). Apesar do conflito as características dominantes da globalização são derivadas da globalização hegemônica.

A globalização para Boaventura Santos também é caracterizada pelo direcionamento do sistema financeiro, pelo investimento em escala global, produção com processo flexível e multilocal, custos baixos de transporte, grande avanço na tecnologia de informação, desregularão das economias nacionais e crescente importância das agências financeiras.

Boaventura Santos concorda que o Consenso de Washington é um elemento importante 
Congressoem

Desenvolvimento Social

\section{Desafios à Democracia, Desenvolvimento e Bens Comuns}

nesse mercado global, garantindo aos capitalistas transnacionais, em acordo com as elites locais e a burguesia estatal, promoverem uma redistribuição da massa da população para eles mesmos, acentuando a desigualdade. A partir dos termos do consenso o Estado-nação perde a sua centralidade e se enfraquece enquanto unidade econômica, política e social, se submetendo aos interesses dos países centrais, Santos chega a considerar a ocorrência de uma "internacionalização do Estado nacional." (2002, p.38).

A liberação do mercado, privatizações, desativação das agências regulatórias, a "flexibilização" salarial, a redução de ações relativas ao bem estar social, a negligencia com temas ambientais, reforma educacionais de âmbito tecnicista e o estado intervindo para deixas de intervir são alguns aspectos contidos nesse processo de globalização.

A tendência geral consiste em substituir até o máximo que for possível o princípio do Estado pelo princípio do mercado e implica pressões por parte dos países centrais e das empresas multinacionais sobre os países periféricos e semiperifériocos no sentido de adoptarem ou de adaptaram às transformações jurídicas e institucionais que estão a ocorrer no centro do sistema mundial. (SANTOS, 2002, p.39)

Boaventura entende que o Consenso de Washington abrange na verdade três outros consensos: o consenso do Estado fraco, da democracia liberal e do primado do direito.

O consenso do Estado fraco compreende que o Estado é o oposto da sociedade civil, portanto, seu inimigo potencial, então o seu tamanho deveria ser reduzido visando o fortalecimento da sociedade, no entanto, como referido por Boaventura, diminuir a regulação do Estado implica em uma atividade regulatória possível apenas para um Estado forte, o que torna essa ideia contraditória.

O consenso da democracia liberal prevê liberdade econômica e política, eleições e mercado livres, todavia esse modelo é, para Boaventura Santos, aplicado de forma monolítica em situações muito distintas e por ser financiado pelo mercado global, tende na verdade a uma versão caricatural da democracia liberal.

Já quanto consenso do primado do direito e do sistema judicial, o neoliberalismo reclama um novo quadro legal adequado a liberdade do mercado, dos investimentos e sistema financeiro. A responsabilidade central do estado seria criar um sistema legal que seja capaz de garantir juridicamente a ação de atores do mercado mundial.

A globalização não e linear e inequívoca para Santos, mas fruto de um processo dotado de dispositivos ideológicos com intencionalidades especificas que tendem para a ideia de que a essa ocorre de forma automática e irreversível. "A falácia consiste em transformar as causas da globalização em efeitos da globalização" (SANTOS, 2002, p.50). A globalização na realidade seria um processo resultante de um conjunto de fatos gerados por decisões políticas dos estados centrais e não algo que ocorreu naturalmente mas sim de forma em certo ponto impositivamente.

Boaventura Santos entende que a globalização produz discursos plurais, então esse autor busca uma reflexão teórica que considere "complexidade dos fenômenos que ela envolve e a disparidade dos interesses que nela se confrontam” (2002, p.54). Sua proposta teórica parte de 
Congressoem

Desenvolvimento Social

\section{Desafios à Democracia, Desenvolvimento e Bens Comuns}

três contradições encontradas na globalização: a primeira é a contradição entre a globalização e localização, onde as interações tendem a desterritorialização, mas ao mesmo tempo propiciam o fortalecimento identidades locais e regionais, como um direito as raízes e culturas ancestrais; a segunda é a contradição entre o Estado-nação e não estado, o Estado seria uma estrutura obsoleta e em vias de extinção? Ou uma entidade central na política que permite a desregulação exigida pelo consenso neoliberal? A terceira contradição é político-ideológica, entre os que creem que a globalização é o triunfo do capitalismo e os que pensam que se trata de uma nova oportunidade para de ampliar a solidariedade transnacional e a luta anticapitalista.

Diante dessas contradições, Boaventura Santos entende que o que designamos como globalização se compõe de distintos processos globais, ou seja, compreende a existência de:

[...] diferentes, e por vezes, contraditórias, globalizações... não há uma entidade única chamada globalização; existem, em vez disso, globalizações; em rigor, esse termo só deveria ser usado no plural (2002, p.55-56).

Uma teoria adequada para tratar a globalização deve ser capaz de dar conta das pluralidades e contradições dos sues processos Boaventura propõe seguir um modelo baseado no conceito de um sistema mundial em transição:

Em transição porque contém em si o sistema mundial velho, em processo de profunda transformação, e um conjunto de realidades emergentes que podem ou não conduzir a um novo sistema mundial, ou há qualquer entidade nova, sistêmica ou não... Trata-se de uma situação caracterizada pela turbulência e pela explosão de escalas [...] uma teoria aberta às possibilidades de caos. (2002, p.56)

Por fim o referido autor considera a existência de duas formas básicas de globalização, a hegemônica, capitalista e neoliberal e uma contra-hegemônica, uma resistência caracterizada oriunda da "promoção de economias locais e comunitárias, economias de pequena escala, diversificadas, auto sustentáveis, ligadas a forças exteriores, mas não dependente delas" (SANTOS, 2002, p.72). No cenário capitalista global a globalização contra-hegemônica representa a luta pela distribuição democrática da riqueza, atentando para a cidadania individual e coletivamente.

\section{MILTON SANTOS}

Milton Santos (2000) propõe três visões gerais da globalização: como nos fazem vê-la, como é de verdade e como pode vir a ser. Na primeira, como nos fazem vê-la, a globalização é uma fabula onde fantasias são repetidas como o intuito de se tornarem uma interpretação única que favorece o mercado em detrimento da população em geral. Na segunda, como é de verdade, é uma perversidade que impõe um crescente desemprego, aumento da pobreza, diminuição do salário médio, generalização da fome, desabrigo, mortalidade infantil, doenças e dificuldades no acesso a educação de qualidade. Na terceira, como pode vira ser, Milton Santos 
Congressoem

Desenvolvimento Social

\section{Desafios à Democracia, Desenvolvimento e Bens Comuns}

acredita que uma globalização mais humana vai surgir partir de uma nova mistura de raças, povos, culturas e gostos; uma mistura de filosofias em detrimento do racionalismo europeu, um maior dinamismo entre pessoas e filosofias devido a concentração populacional e a emergência de uma cultura popular utilizando meios antes restritos a cultura de massa.

Para esse autor a globalização pode ser definida como o:

[...]ápice do processo de internacionalização do mundo capitalista [...]Ela é também o resultado das ações que asseguram a emergência de um mercado dito global, responsável pelo essencial dos processos políticos atualmente eficazes.(2002, p.12)

Milton Santos entende que a globalização tem as seguintes características: uma unidade técnica baseada em avanços da cibernética, eletrônica e informática que propicia a comunicação entre diferentes técnicas e assegura a simultaneidade das ações controladas pelos "donos" da velocidade e um motor único que é a mais-valia universal onde a produção se dá em escala mundial através de multinacionais, há uma mundialização do produto, crédito, do dinheiro, da informação e do consumo.

O capitalismo pode ser dividido em períodos de estabilidade antecedidos e sucedidos por crises, para Milton Santos o período atual é diferente, pois é um período e uma crise de forma simultânea, pois apresenta características de ambos: "Trata-se, porém, de uma crise persistente dentro de um período com características duradouras, mesmo se novos contornos aparecem." (2000, p.17).

Essa unificação do mundo promovida pela globalização é perversa para a maior parte da humanidade. A competitividade a partir da produção e do consumo gera um novo totalitarismo onde há uma violência estrutural dos estado e empresas sobre os indivíduos. Há um encolhimento das funções sociais e políticas do estado com ampliação da pobreza enquanto se amplia o poder político das empresas na regulação da vida social.

A informação que é oferecida a humanidade e a emergência do dinheiro em estado puro se tornam o motor da vida social e constituem a violência central da ideologia hegemônica e seu discurso único de mundo que é à base de novos totalitarismos ou globalitarismos. As condições técnica permitiram a ampliação do conhecimento através da tecnologia da informação, contudo essa tecnologia é utilizada por uns poucos atores em função de objetivos particulares. São apropriados por estados e empresas que aprofundam a desigualdade. A informação manipula ao invés de esclarecer. Para Milton Santos:

a violência estrutural resulta da presença e das manifestações conjuntas, nessa era da globalização, do dinheiro em estado puro, da competitividade em estado puro e da potencia em estado puro, cuja associação conduz à emergência de novos totalitarismos e permite pensar que vivemos numa época de globalitarismo muito mais do que globalização(2000, p.27)

A perversidade na globalização é sistêmica, a fome é permanente e generalizada, há falta água potável, ampliação do numero de refugiados, banalização do fenômeno dos sem teto, 
Congressoem

Desenvolvimento Social

\section{Desafios à Democracia, Desenvolvimento e Bens Comuns}

aumento da pobreza e deteriorização do valor do trabalho. O processo político passa cada vez mais a ser atributo de empresas. A globalização gerou uma ruptura do processo de evolução social sem precedentes. "A globalização mata a noção de solidariedade, a ciência e a técnica trabalham para o mercado e não para a humanidade em geral.” (SANTOS, 2000, p.32)

\section{PERPECTIVAS DE DESDOBRAMENTOS.}

Diante das análises feitas por Boaventura Sousa Santos e Milton Santos são quase inevitáveis às indagações acerca dos rumos que os processos de globalização nos levarão, esses autores expuseram suas reflexões sobre esse assunto em seus textos, sobre as quais faremos um breve exame.

Boaventura Sousa Santos entende que esse período atual é de transição, não "como uma mera justaposição de características modernas e emergentes já que a combinação entre elas altera a lógica interna de umas e outras" (2002, p.89). Como processo transição espera-se que resulte em uma transformação, Boaventura propõe duas leituras acerca dessa possibilidade: a paradigmática e a subparadigmática.

A leitura paradigmática pressupõe que entre os anos 1960 e 1970 teve início uma transição mundial que culminaria em um novo paradigma social, em que o "colapso dos mecanismos de ajustamento estrutural abre um vasto terreno para experimentação social e para escolhas históricas reais, muito difíceis de prever" (2002, p.90).

A leitura subparadigmática entende que o processo atual é um mero ajustamento estrutural:

[...]no qual o capitalimo não parece dar mostra de falta de recursos ou imaginação adequados. $\mathrm{O}$ ajustamento é significativo porque implica a transição de um modo de regulação ("fordismo") para outro (ainda por nomear; "pósfordismo"), como vem sendo sustentado pelas teorias da regulação. (SANTOS, 2002, p.91)

A leitura paradigmática pressupõe uma tensão no regime de acumulação, haveria, portanto, uma crise civilizatória profunda, talvez com a superação do próprio capitalismo; já a leitura subparadigmática, prevê um ajustamento do sistema, ainda que de forma provisória e insatisfatória, entendendo que o capitalismo tem resolvido com algum sucesso suas crises.

A leitura paradigmática é mais apocalíptica quanto aos perigos e colapsos, mas ao mesmo tempo mais otimistas frente às novas possibilidades, com "a inauguração de uma nova era de solidariedade global ou até mesmo cósmica.” (SANTOS, 2002, p.94).

Em uma visão subparadigmática, se entende que as mudanças proporcionadas pelas transformações globais na economia, apesar de relevantes, não conduzem a uma novo paradigma, mas: "Expressam apenas a turbulência temporária e o caos parcial que acompanham normalmente qualquer mudança nos sistemas rotinizados. (SANTOS, 2002, p.94)

Boaventura Santos finaliza seu texto afirmando:

As minhas análises do tempo presente, a minha preferência pelas acções 
Congressoem

Desenvolvimento Social

\section{Desafios à Democracia, Desenvolvimento e Bens Comuns}

transformadoras e, em geral, a minha sensibilidade - e esta é a palavra exata - inclinam-me a pensar que as leituras paradigmáticas interpretam melhor a nossa condição no inicio do novo milênio do que as subparadigmáticas." (2002. p.94).

Milton Santos vê na globalização;

[...] a possibilidade de produção de um novo discurso, de uma nova metanarrativa, de um novo grande relato [...] A universalidade deixa de ser apenas uma elaboração abstrata na mente dos filósofos para resultar da experiência ordinária de cada homem.(2000, p.11).

Esse autor acredita que a um limite para essa globalização perversa. A crescente compreensão por parte dos países pobres da perversidade do sistema resulta em seu repúdio e uma busca por novas soluções não centradas no dinheiro, mas na figura do próprio homem como um motor de um mundo novo. Milton Santos considera a possibilidade de uma revanche da cultura popular sobre acultura de massa, com a cultura popular sendo difundida pelos instrumentos próprios da cultura de massa e atuando como porta voz das minorias dos pobres e excluídos. $\mathrm{O}$ autor pensa em uma reemergência das massas, onde a centralidade ocupada pelo dinheiro, que deixa o homem como elemento residual, será substituída por uma realidade onde o homem ocupe lugar privilegiado.

A nova paisagem social resultaria do abandono e da superação do modelo atual e sua substituição por outro, capaz de garantir para o maior número a satisfação das necessidades essenciais a uma vida humana digna, relegando a uma posição secundária necessidades fabricadas, impostas por meio da publicidade e do consumo conspícuo.(2000, p.72)

Milton Santos considera certo que rupturas nas margens do capitalismo são capazes de gerar mudanças no sentido de se alcançar uma nova globalização, entendendo obviamente que o modelo atual não é irreversível, pois é um modelo imposto ideologicamente. O futuro serão muitos e resultarão de arranjos diferente segundo nosso grau de consciência e vontade. $\mathrm{O}$ autor finaliza de forma otimista: "Agora que estamos descobrindo o sentido de nossa presença no planeta, pode-se dizer que a história universal verdadeiramente humana está, finalmente, começando."(2000, p.85).

No geral Milton Santos é mais otimista em relação aos desdobramentos possíveis do processo de globalização, ele acredita em uma possibilidade concreta de emancipação do ser humano, onde o homem se torna o centro de uma sociedade consciente e universal. Boaventura de Sousa Santos, contudo, apesar de tender a leitura paradigmática, para qual chegaremos a uma nova sociedade, não descarta a possibilidade de que a atual conjuntura seja apenas mais uma das inúmeras crises apresentadas pelo capitalismo. 


\section{Congressoem}

Desenvolvimento Social

\section{Desafios à Democracia, Desenvolvimento e Bens Comuns}

\section{REFERÊNCIAS}

ALVAREZ, Marcos César. Cidadania e direitos num mundo globalizado. In: Perspectivas, São Paulo, n. $22,95-107,1999$.

DUMÉNIL, Gerárd; LÉVY, Dominique. Neoliberalismo - Neo-imperialismo. In: Economia e sociedade, Campinas, v.16, $\mathrm{n}^{\mathrm{o}}$ 1, 2007, p.1-19.

GIDDENS, Anthony. As conseqüências da modernidade. São Paulo: Editora Unesp, 1991, p. $69-70$

IANNI, Octávio. Globalização: novo paradigma das ciências sociais. In: Estudos avançados, v8, nº21, 1994, 147-163

IANNI, Octávio. Teorias da globalização. Rio de Janeiro: Civilização brasileira, 2001.

MATOS, Sidney Tanaka S. Conceitos primeiros de neoliberalismo. In: Mediações, v,13, no 1-2, 2008. P. 192-213.

SANTOS, Boaventura de Sousa. Os processos da globalização. In: SANTOS, Boaventura de Sousa. (org.) A globalização e as ciências sociais. São Paulo: Cortés, 2002, p.25-102.

SANTOS, Milton. Por uma outra globalização: do pensamento único a consciência universal. Rio de Janeiro: Record, 2000. 